\title{
Editorial
}

\section{Acute medicine: the physician's role. A working party report of the Federation of Royal Colleges of Physicians of the United Kingdom}

A working party for the Federation of Royal Colleges of Physicians of the United Kingdom was established to make recommendations on ways of improving the quality of care for patients admitted with medical emergencies, and also to "re-invigorate" physicians who carry the burden of the acute workload. Before commenting on the report, ${ }^{1}$ consider these two scenarios.

Scenario 1 A multiply injured patient is in the resuscitation room. The response is well practised, senior anaesthetic, surgical and orthopaedic doctors attend and under the direction of a senior accident and emergency (A\&E) team leader the treatment plan is instigated.

Scenario 2 There is a critically ill patient with an acute medical condition in the emergency department. An acute medical care team assemble including a senior physician, an intensivist and $A \& E$ senior staff.

The first scenario is a reality in many hospitals. The second may be a vision of the ideal but few of those working in UK Emergency Departments (A\&E departments) will have experience of such a service. The "acute physician" in many hospitals is still an overworked senior house officer (SHO, postgraduate year 1-3). Consultants and specialist registrars (SpR, postgraduate year 3-8) often have routine clinics, ward rounds and other commitments that make it difficult to respond to emergencies. Increasingly the first few hours of care of the critically ill medical patient is being delivered by A\&E senior staff. There is a growing body of evidence that effective, time critical medical treatment can be effectively delivered in an A\&E setting. ${ }^{2}$

Against this background it will surprise some A\&E consultants to learn that "Traditionally, A\&E consultants were not adequately trained in emergency medicine". ${ }^{1}$ This may have been the case 20 years ago but increasingly the workload and training in A\&E is heavily biased towards acute general medicine. Critically ill medical patients attending an average A\&E department will outnumber critical trauma and surgical emergencies by at least 5:1. Furthermore, the view of the working party is that a CCST in acute general medicine is a prerequisite for taking responsibility for acute medical patients. This comment on the relative expertise and involvement of the two specialties does not however seem to reflect the day to day reality in many of our hospitals. Though there are some consultant physicians who are heavily involved in the acute care of the seriously ill, the majority are not. It is therefore hard to see how the report's recommendation of senior involvement in "post take ward round" every 24 hours is going to change current practice.

\section{Implications of the report for $A \& E$}

The report identifies many of the problems with the current admission process (too few beds, poor access to investigations, lack of community support to unblock beds) and gives recommendations on how these might have been overcome. There is little new in this "wish list" and all of these will require an increase in resources: probably the real obstacle to improving care for medical patients. The report does acknowledge the key importance of $\mathrm{A} \& \mathrm{E}$ and the necessity to work closely with internal medicine. It identifies the need for the Faculty of A\&E Medicine and the medical Royal Colleges to define the training requirements for those doctors who wish to be involved in "extended responsibility" for medical patients. This is a welcome step as there are a number of $\mathrm{A} \& \mathrm{E}$ trained doctors who wish to do this work and some already are in charge of admission wards. It is important that these discussions take place as soon as possible. There is an obvious need for committed well trained doctors but such training takes time. The need is here and now and growing.

Equally many will welcome the recommendation that there should be audits of the care of acute medical conditions. Trauma audit techniques are well advanced as are surgical and obstetric audits but there is no equivalent national framework for medical emergencies.

The document rightly recognises the importance of $\mathrm{A} \& \mathrm{E}$ medicine but is disappointing in the lack of recognition of the reality that much of the care of critically ill patients takes place in $\mathrm{A} \& \mathrm{E}$ departments. It rightly points to cooperation as the way forward for the future but that cooperation should be based on recognition of the skills, training and service provision that already exist. A\&E doctors should be seen as equal partners in these initiatives.

Perhaps soon we will see the formation of "multidisciplinary emergency medical teams" with A\&E specialists, acute physicians and intensivists combining to provide optimum care for the critically ill medical patient. Then the vision of our second scenario will become reality.

RICHARD D HARDERN

The General Infirmary at Leeds, Great George Street, Leeds, West Yorkshire LS1 3EX (rhardern@ulth.northy.nhs.uk)

1 Acute medicine: the physician's role. A working party report of the Federation of Royal Colleges of Physicians of the United Kingdom. London: Royal Colleges of Physicians of the United Kingdom, 2000.

2 Edhouse JA, Sakr M, Wardrope J, et al. Thrombolysis in acute myocardial infarction: the safety and efficiency of treatment in the accident and emergency department. F Accid Emerg Med 1999;16:325-30. 